\title{
Brain imaging of children with postischemic seizures
}

\author{
${ }^{{ }^{*}, 3}$ Maria Moldovanu, ${ }^{1,2}$ Cornelia Calcii \\ ${ }^{1}$ Department of Neurology, Nicolae Testemitanu State University of Medicine and Pharmacy \\ ${ }^{2}$ Department of Pediatrics, Institute of Mother and Child, ${ }^{3} \mathrm{MRI}$ and CT Department of German Center for Diagnostics \\ Chisinau, the Republic of Moldova
}

Authors' ORCID iDs, academic degrees and contributions are available at the end of the article

*Corresponding author - Maria Moldovanu, e-mail: Maria.Moldovanu@cdg.md

Manuscript received July 16, 2021; revised manuscript August 18, 2021; published online September 10, 2021

\begin{abstract}
Background: Arterial ischemic stroke is a rare disease found in the pediatric population, with an incidence of 2-13 out of 100000 children per year. Children develop seizures more often in the initial phase of stroke compared to adults.

Material and methods: There have been included children examined by brain MRI hospitalized in the department of neurology (early aged children), Hospital of Mother and Child Health Care, with a diagnose of ischemic stroke, with an acute focal neurological syndrome installed. The children not having an imagistic confirmation of arterial ischemic stroke were excluded.

Results: The study lot was composed of 78 children, who corresponded to all the inclusion criteria for this study (Tab.1). The children were examined by $1.5 \mathrm{~T}$ and $3 \mathrm{~T}$ MRI with multiplanar assessment of brain structures. In cases with acute / subacute stroke specific diffusion sequences (DWI and ADC) were applied to determine the type of stroke, approximate installation period. Ischemic brain lesions on MRI are presented by areas of cytotoxic edema in acute/ subacute cases, in chronic / late cases by the appearance of changes such as lacunar defects, areas of encephalomalacia.

Conclusions: The vast majority of children with brain lesions on MRI have convulsions with early onset and have developed recurrent seizures after the acute phase of stroke.

Key words: ischemic stroke, MRI, brain.
\end{abstract}

\section{Cite this article}

Moldovanu M, Calcii C. Brain imaging of children with postischemic seizures. Mold Med J. 2021;64(3):28-31. https://doi.org/10.52418/moldovanmed-j.64-3.21.05.

\section{Introduction}

Arterial ischemic stroke is a rare disease found in the pediatric population, with an incidence of 2-13 out of 100000 children per year. According to the evaluation of studies in the literature [1-3] a correlation was observed between the early onset of seizures and the arterial ischemic stroke, them being diagnosed in $19 \%$ up to $44 \%$ after stroke. Children develop seizures more often in the initial phase of stroke compared to adults $[1,3]$. MRI neuroimaging is very informative for establishing the diagnosis of stroke. The aim of the study: evaluation of brain ischemic lesions in children with seizures.

\section{Material and methods}

There have been included children examined by brain MRI hospitalized in the department of neurology (early aged children), Hospital of Mother and Child Health Care, with a diagnose of ischemic stroke, with an acute focal neurological syndrome installed. The children not having an imagistic confirmation of arterial ischemic stroke were excluded.

The types of seizures are defined after the International
League Against Epilepsy criteria. Early-onset seizures were defined as seizures that appear up to 7 days after the arterial ischemic stroke. Late-onset seizures appear later than 7 days after the onset of the ischemic stroke, and post arterial ischemic stroke epilepsy can be defined by the presence of more than 2 seizures that emerged after the acute phase of arterial ischemic stroke (longer than 1 month).

In order to get the most truthful results the $t$ student test was applied for comparing continuous variables and the $\chi^{2}$ test for discrete variables. We have used the Kaplan-Meier estimator for determining the cumulative incidence of previously unprovoked seizures. The log-rank test was used in order to compare the risk of appearance of subsequent unprovoked seizures at children with and without early-onset seizures. Values with $\mathrm{p}<0.05$ were considered statistically significant values.

\section{Results}

The study lot was composed of 78 children, who corresponded to all the inclusion criteria for this study (tab.1). Early-onset seizures were present at 20 children out of 78 $(25.6 \%)$, the average age of debut being $1.4 \pm 1.9$ years, the 
Table 1. Characteristic of patient

\begin{tabular}{|c|c|c|c|c|c|c|c|}
\hline \multirow[t]{3}{*}{ Seizures } & \multirow[b]{3}{*}{ № } & \multirow[b]{3}{*}{$\mathrm{N}(\%)$} & \multirow{2}{*}{\multicolumn{2}{|c|}{ With early onset }} & \multirow{2}{*}{\multicolumn{2}{|c|}{ With late onset }} & \multirow[b]{3}{*}{$\mathrm{P}$} \\
\hline & & & & & & & \\
\hline & & & № & $\mathrm{N}(\%)$ & \multirow{2}{*}{$\begin{array}{l}\text { № } \\
58\end{array}$} & $\mathrm{~N}(\%)$ & \\
\hline Number of patients & 78 & $(100)$ & 20 & $(25.6)$ & & $(74.4)$ & \\
\hline Age of onset & & & & & & 6.2 & $<0.001$ \\
\hline \multicolumn{8}{|l|}{ Risk factors } \\
\hline Cardiac Disease & 23 & $(29.5)$ & 7 & $(35.0)$ & 16 & $(27.6)$ & 0.58 \\
\hline Coagulopathy & 20 & $(25.6)$ & 6 & $(30.0)$ & 14 & $(24.1)$ & 0.77 \\
\hline Vascular pathologies & 19 & $(24.4)$ & 4 & $(20.0)$ & 15 & $(25.9)$ & 0.77 \\
\hline Infections & 11 & $(14.1)$ & 6 & $(30.0)$ & 5 & (8.6) & 0.03 \\
\hline Vasculites & 7 & $(9.0)$ & 0 & (0) & 7 & $(12.1)$ & 0.18 \\
\hline Methabolic Disease & 6 & (7.7) & 3 & $(15.0)$ & 3 & $(5.2)$ & 0.17 \\
\hline Hemathologic Disease & 2 & (2.6) & 0 & (0) & 2 & (3.4) & 1.0 \\
\hline \multicolumn{8}{|l|}{ Cortical involvment } \\
\hline Cortical involvment & 56 & $(71.8)$ & 19 & $(95.0)$ & 37 & $(63.8)$ & 0.01 \\
\hline Bylateral localization & 15 & $(19.2)$ & 5 & (25) & 10 & $(17.2)$ & 0.52 \\
\hline \multicolumn{8}{|l|}{ General State } \\
\hline Focal neurological impairment & 66 & $(84.6)$ & 12 & (60) & 54 & $(93.1)$ & 0.001 \\
\hline Alteration of consciousness & 18 & $(23.1)$ & 9 & $(45.0)$ & 9 & $(15.5)$ & 0.01 \\
\hline \multicolumn{8}{|l|}{ Duration of the Study } \\
\hline Average duration (month) & \multicolumn{2}{|c|}{$55.6 \pm 48.4$} & \multicolumn{2}{|c|}{$73.0 \pm 52.2$} & \multicolumn{2}{|c|}{$49.0 \pm 45.6$} & 0.62 \\
\hline
\end{tabular}

children being younger than the ones who were not diagnosed with this type of seizures, $3.2 \pm 6.2$ years, $\mathrm{p}<0.001$. Out of them, for 20 children (90\%), the seizures were the first manifestations of the clinical picture.

The repartition of this convulsive access after the structure was as follows: focal seizures diagnosed at 15 children (75\%), 3 children had generalized seizures (15\%) and in 2 cases the debut could be determined neither as focal nor as generalized (10\%). Out of all analyzed cases the frequent (daily) seizures were determined at 12 children (60\%). Cases with only one seizure at the debut of the ischemic stroke were noted at 5 children (25\%) and 3 children have developed status epilepticus.

In the study group, in the EEG picture, the following modifications were noted: slow diffusion of the route in 8 cases (40\%), focal slowing in 7 cases (35\%) and epileptiform activity in 5 cases (25\%).

Children who had developed early-onset seizures, in comparison with those who had late-onset seizures have a predisposition to infections as a risk factor for arterial ischemic stroke (30\% vs $8.6 \%, \mathrm{p}=0.03$ ), more frequent cortical affectations (95\% vs $63.8 \%, \mathrm{p}=0.01$ ), and knowledge disturbances from the beginning ( $45 \%$ vs $15.5 \%, \mathrm{p}=0.01$ ). The neuronal focal shortage was more frequent at children with late-onset seizures ( $60 \%$ vs $93.1 \%, \mathrm{p}=0.001)$.
The study duration was $53.7 \pm 48.8$ months. The earlyonset seizures did not influence the mortality after the acute phase of arterial ischemic stroke ( $0 \%$ versus $8.6 \%, \mathrm{p}=0.32)$.

During 4.5 years, 13 children (65\%) out of the group with early-onset seizures and 5 children (8.6\%) out of the ones without early-onset seizures were diagnosed with unprovoked seizures. During all these years, the cumulative incidence of the development of the repeated seizures in the both groups was $52.5 \%$ and $3.5 \%$ for 1 year after the onset, $52.5 \%$ and $6.2 \%$ for 2 years after the onset and $72.3 \%$ and $14.4 \%$ in 4.5 years. The children from the early-onset seizures group have developed a more significant risk of the appearance of repeated seizures during the years after the arterial ischemic stroke, in comparison with those with lateonset seizures $(\mathrm{p}<0.001)$. The majority $(67 \%)$ of the subsequent repeated crises had their onset during the first postarterial ischemic stroke year vs $27 \%$ after 2 years after the evolution.

The children were examined by $1.5 \mathrm{~T}$ and $3 \mathrm{~T}$ MRI (Siemens Avanto and Skyra) with multiplanar assessment of brain structures. In cases with acute / subacute stroke specific diffusion sequences (DWI and ADC) were applied to determine the type of stroke, approximate installation period [4].

Diagnostic efficiency can be improved by administering 
the intravenous contrast agent. In children younger than 7-8 years, sedation was performed during the investigation, of about 15-20 minutes with the involvement of a team of radiologist and anesthesiologist available for this procedure.

Stroke in children has significant neurological deficits. Ischemic brain lesions on MRI are presented by areas of cytotoxic edema in acute / subacute cases, in chronic / late cases by the appearance of changes such as lacunar defects, areas of encephalomalacia (fig. 1).

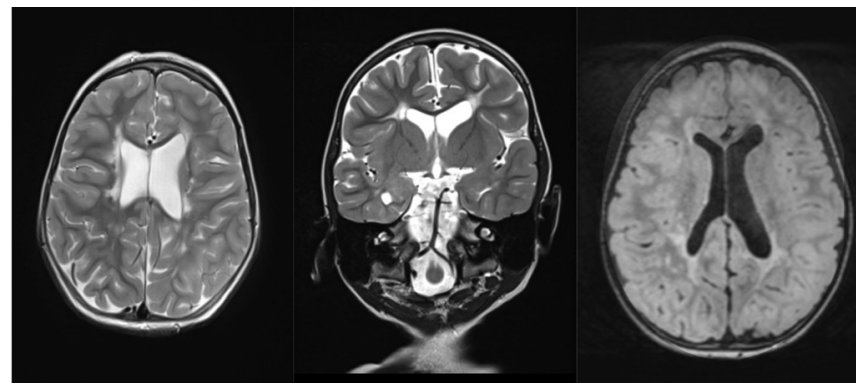

Fig. 1. MRI pictures (TW2ax, cor and FLAIR ax) characteristic for areas of chronic postischemic encephalolomalacia of bilateral periventricular white matter, with ex-vacuo dilatation of the lateral ventricles

More frequently, the bilateral (fig. 2) or unilateral involvement of the basal nuclei is attested (fig. 3). In the sequences sensitive to the determination of hemorrhage (SWI type), there are hemeosiderin inclusions in the ischemic region.

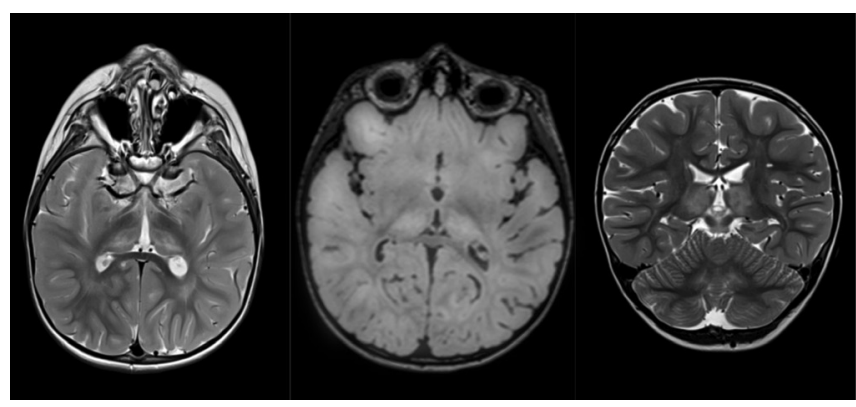

Fig. 2. MRI pictures (TW2ax, FLAIR ax and TW2cor) characteristic for ischemic stroke with involvement of the bilateral thalamus and periventricular white matter

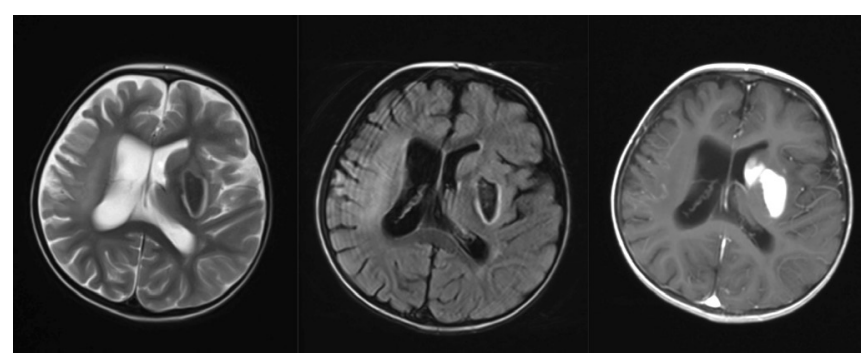

Fig. 3. MRI pictures (TW2, FLAIR and TW1 postcontrast) characteristic for arterial ischemic stroke in the teritory of the arteria cerebri media (left)involving left basal ganglias. Atroficglyotic modifications in the fronto-temporal lobes (right)

\section{Discussion}

In this study there was made a conclusion that the frequency of children who have presented early-onset seizures after the arterial ischemic stroke is $25.6 \%$, in comparison with other studies that present values starting with $19 \%$ up to $44 \%[1,5]$. Also in the existing studies it is proved that the incidence of this kind of seizures is higher amongst the children than amongst the adults $[3,6]$. In the given study this fact was confirmed through the higher incidence of seizures among the younger children, in comparison with those who are older.

As the result of the study a connection between earlyonset seizures and post-arterial ischemic stroke epilepsy was determined. The cumulative incidence of the development of late-onset seizures was of $72.3 \%$ for 4.5 years of follow-up. Children with early-onset seizures have developed post-arterial ischemic stroke epilepsy in $60 \%$ of the cases. In the existent studies it was determined that children with post-arterial ischemic stroke seizures were more likely to have epilepsy in the future, the fact confirmed in this study too. The aim of this study was to determine the risk factors for the recurrence of the post-arterial ischemic stroke debut strokes in the future, but there were not found any statistically significant differences linked with the age or the sex of the children implied in this study or with the usage of the antiepileptic means in a prophylactic purpose. A lot of the existent studies have shown that the antiepileptic drugs used in the initial phases of the arterial ischemic stroke with the purpose of stopping the acute seizures do not reduce the risk of the development of epilepsy $[7,8]$. In addition, the previous studies concerning the adult population have proved that the usage of antiepileptic medicines in the initial phases, in order to prevent the recurrence of seizures is not necessary $[7,8,9]$. However, it is necessary to mention that the therapeutic tactics is different in the adult vs pediatric population and additional studies are required for proving this hypothesis.

\section{Conclusions}

In the course of this study, it was found that the vast majority of children with brain lesions on MRI have convulsions with early onset and have developed recurrent seizures after the acute phase of stroke. There are many challenges and complications in the evaluation of these children, being often the need for sedation to obtain informative images.

It is necessary to study further the relationship between seizures and the risk of developing post-stroke epilepsy, as well as to develop an effective method of preventing subsequent recurrent seizures.

\section{References}

1. deVeber GA, MacGregor D, Curtis R, Mayank S. Neurologic outcome in survivors of childhood arterial ischemic stroke and sinovenous thrombosis. J Child Neurol. 2010;15(5):316-324. doi: 10.1177/088307380001500508. 
1. Thurman DJ, Beghi E, Begley CE, et al. Standards for epidemiologic studies and surveillance of epilepsy. Epilepsia. 2011;52(Suppl 7):2-26. doi: 10.1111/j.1528-1167.2011.03121.x.

2. Zahuranec DB, Brown DL, Lisabeth LD, Morgenstern LB. Is it time for a large, collaborative study of pediatric stroke? Stroke. 2015;36(9):1825-9. doi: 10.1161/01.STR.0000177882.08802.3c.

2. Manea M, Golea G, Mălăescu R. [Arterial ischemic stroke in children]. Revista de Neurologie și Psihiatrie a Copilului și Adolescentului din Romania [Rom J Child Adolesc Neurol Psychiatr]. 2014;17(3):27-38. Romanian.

3. Ferguson PL, Smith GM, Wannamaker BB, Thurman DJ, Pickelsimer EE, Selassie AW. A population-based study of risk of epilepsy after hospitalization for traumatic brain injury. Epilepsia. 2010;51(5):891-898 doi: $10.1111 / j .1528-1167.2009 .02384 . x$.
4. Beslow LA, Abend NS, Gindville MC, et al. Pediatric intracerebral hemorrhage: acute symptomatic seizures and epilepsy. JAMA Neurol. 2013;70(4):448-54. doi: 10.1001/jamaneurol.2013.1033.

5. Lossius MI, Ronning OM, Slapo GD, Mowinckel P, Gjerstad L. Poststroke epilepsy: occurrence and predictors - a long-term prospective controlled study. Epilepsia. 2011;46(8):1246-1251. doi: 10.1111/j.15281167.2005.57904.x.

6. Fullerton HJ, Wu YW, Sidney S, Johnston SC. Risk of recurrent childhood arterial ischemic stroke in a population-based cohort: the importance of cerebrovascular imaging. Pediatrics. 2007;119(3):495-501. doi: 10.1542/ peds.2006-2791

7. Leone MA, Tonini MC, Bogliun G. Risk factors for a first epileptic seizure after stroke: a case control study. J Neurol Sci. 2009;277(1-2):138-142. doi: 10.1016/j.jns.2008.11.004.

\section{Authors' ORCID iDs and academic degrees}

Maria Moldovanu, MD, PhD Applicant - https://orcid.org/0000-0002-3911-3067

Cornelia Calcii, MD, PhD, Associate Professor of Neurology - https://orcid.org/0000-0002-2608-2417

\section{Authors' contribution}

MM conceptualized the idea, conducted literature review and wrote the manuscript; CC collected and interpreted the data. Both authors approved the final version.

\section{Funding}

This study was supported by German Center for Diagnostic in Chisinau. The authors are independent and take responsibility for the integrity of the data and accuracy of the data analysis.

\section{Ethics approval and consent to participate}

The study was approved by the Research Ethics Committee of Nicolae Testemitanu State University of Medicine and Pharmacy (protocol No 69 of March 21, 2017). An informed consent from all participants in the study was obtained.

\section{Conflict of interests}

No competing interests were disclosed. 